\title{
Evaluation of Collection and Distribution of Samples for Histological, Stereological Analysis and Cell Culture of Canine Mast Cell Tumors*
}

\author{
Samanta Rios Melo, Thaís Andrade Costa-Casagrande, Julia Maria Matera \\ Department of Surgery, School of Veterinary Medicine, University of São Paulo, São Paulo, Brazil \\ Email: samymelo@usp.br
}

Received September 5, 2012; revised November 1, 2012; accepted November 12, 2012

\begin{abstract}
Objective: To collect high quality, representative tissue material from tumors and manage its distribution to different laboratories. Design: Prospective controlled study. Animals: Thirty-six dogs with mast cell tumors. Procedures: The samples were submitted for the following analyses: stereology; histopathology; cell culture; breakdown for cytogenetic analysis of chromosomes (based on the Boxer breed published genome); Cell lysis for Real Time PCR and quantification of gene expression of CX 43, 32 and E-cadherin in canine mast cells. Results: Cytogenetic chromosome analysis, $90.9 \%$ of the samples were considered to be of good quality. For gene expression quantification of CX 43,32 and E-cadherin in canine mast cell tumors (MCT), $95.5 \%$ of samples were considered to be of good quality. Conclusions and Clinical Relevance: We seek to assess the importance of surgical collection and post-surgical tissue preparation on laboratory testing by collecting surgical material appropriately to allow accurate diagnosis and reliable clinical prognosis and minimize errors caused by inadequate preparation of samples.
\end{abstract}

Keywords: Mast Cell Tumor; Oncologic Surgery; Canine; Tumor Collection; Stereological Analysis

\section{Introduction}

Mast cell tumors are common neoplasia in small animals. This type of neoplasm occurs in several species, including humans, but the major incidence is in canines and felines [1-3]. Mast cell tumors in the dog most commonly develop in the skin. These tumors usually have a variable appearance. In the predominant formation, the mast cell looks similar to a normal cell and is relatively easy to diagnose. Several approaches have been used to define prognosis for mast cell tumors and for other types of canine and feline tumors. Clinical reports, surgical resection $[1,4,5]$ and histological analyses of the tissue, as well as assessment of kinetic parameters such as Ki-67 protein [6,7], BrdU [7], PCNA [8], AgNOR [9]-Argyrophilic nucleolar organiser region, DNA ploidy[10], intratumoral vascular density [11], p53 [12,13], c-KIT [14,15], nuclear morphometry [16], tumor profundity[17], and tumor localization [18]. The most common method used for determining the prognosis of a mast cell tumor is histological gradation [19]. The histological evaluation is also needed for the classification of the tumor and to access surgical margins.

\footnotetext{
*Supported by Fundação de Amparo a Pesquisa do Estado de São Paulo (FAPESP). Presented as an abstract at the 30th Annual Conference of the Veterinary Cancer Society, San Diego-USA, 2010.
}

The diagnosis of mast cell tumors and other tumors depends on the pathologist's access to the material collected from the surgeon. Most cancer diagnoses are determined using cytological (fine need aspiration) and histological (excisional biopsy) evaluations. Consequently, mistakes in the pathological evaluation can lead to inappropriate treatment choices [20,21]. Several methods exist for studying mistakes in anatomopathological evaluation of the samples submitted for analysis. Sampling mistakes are most commonly related to the preparation of the samples (inappropriate storage of the samples, lack of anatomical references for the fragments, and insufficient samples from small tumors) [20-22].

The officially released percentage of error is known to vary significantly, ranging from $1 \%$ to $43 \%$ (averaging between $1 \%$ and $5 \%$ ) in human medicine [22]. Failures are known to originate from the surgeon or his/her team upon transfer of the material for histopathology. In the literature, no studies in human or veterinary medicine have quantified the percentage of error in the histopathological analysis that results from inappropriate preparation of the samples.

Excisional biopsy is used to provide useful information and has diagnostic and prognostic roles in several types of human and canine tumors.. Some care must be 
taken when removing the biopsy sample, and when preparing this sample for sending to laboratorial analysis. Because the slice to be taken for analysis must be a representative sample of the tumor, necrotic and infected areas should be avoided. If possible, a junction of normal tissue with tumor tissue should be sampled. Since surgical procedures for cancer often require 2 - 3 hours of surgery, surgeons often do not have enough time to complete the surgery and prepare the material, and should provide instructions for the team ahead of time so that proper preparation of the sample can be achieved.

Rapid and proper collection of material is very important after the removal of the tissue and is essential for the multidisciplinary analysis of the tumors. Having a specifically dedicated person to perform tissue handling, processing, and distribution to assist surgeons immediately post excision of a tumor improves the quality of specimens collected for histopathological and gene expression analyses. In this work, our objective was to provide a person to collect suitable material and manage its distribution to different laboratories.

\section{Materials and Methods}

The study included dogs that were diagnosed by fine needle aspiration cytology with a mast cell tumor and underwent surgery in the Department of Small Animal Surgery-Veterinary Hospital at the School of Veterinary Medicine, University of São Paulo over a period of 20 months. Thirty-six animals were included, regardless of their age, sex or breed. The surgery was scheduled in advance, and the researcher was present during the surgical procedure. This study was approved by the Institutional Bioethical Committee, and owner consent was obtained for dogs and cats that were enrolled in the study (Protocol number 1014/2006).

Upon removal of the tumor tissue from the animal, the samples were transferred to the collection room, and all of the procedures for the preparation and distribution of the material were performed in this room.

The samples were distributed for the following analyses:

- Cell culture.

- DNA collection for cytogenetic analysis of chromosomes (based on the Boxer breed [23].

- Total cellular RBA collection for quantification of gene expression of CX 43, 32 and E-cadherin in canine mast cells by cell lysis to RT-PCRStereological analysis.

- Histopathological analysis.

\subsection{Dissection and Cleaning of the Tumor}

All of the procedures were performed in a standardized manner to address the variability of the studies and to enable the implementation of the various analyses. In the "collection room", we proceeded in the manner described below and summarized in Table 1.

1) Removal of skin and capsule: We first removed the skin and the fibrous cap of the tumor, which was visible to the naked eye, as shown in Figure 1.

2) Longitudinal cuts: Cuts were made with a thickness of approximately $5 \mathrm{~mm}$, and an average of $5-6$ slices were generated. During the development of this work, we were faced with different tumor formations and sizes, and this step was adapted by altering the size of the cuts based on the size of the tumor (to generate the same number of slices on average for all configurations), as shown in Figure 2.

3) Selection of a number (1 or 2) on the table of random numbers to separate the slices into two fractions to optimize stereological sample collection. Thus, we maintained the selection of samples sought by stereology (in which homogeneous and random samples from all por-

Table 1. Summary of the methods for dissection and sampling.

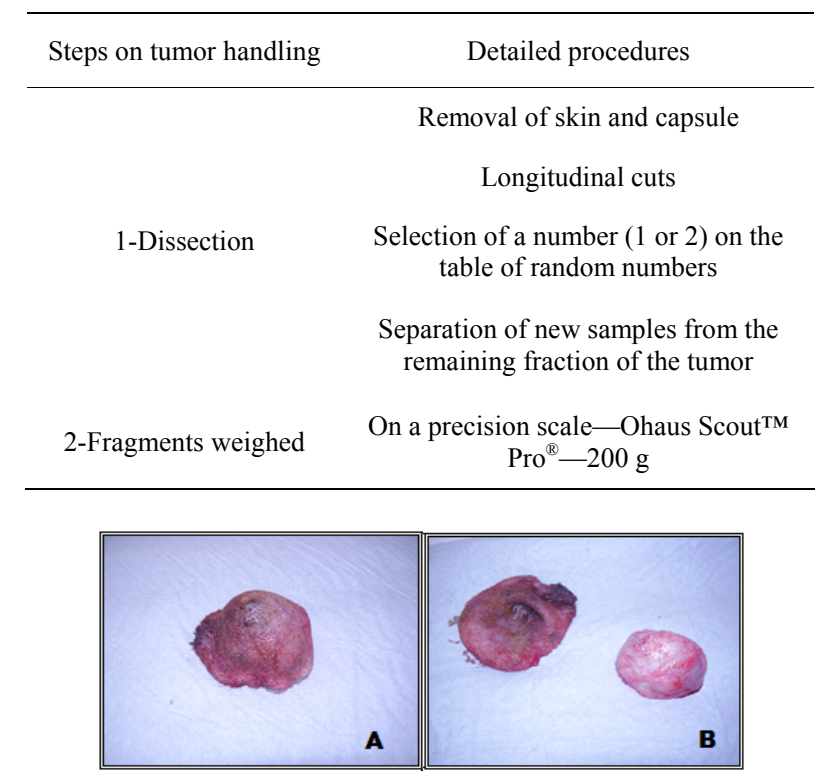

Figure 1. Sample 33-Skin tumor (A); completely dissected and cleaned $(B)$.

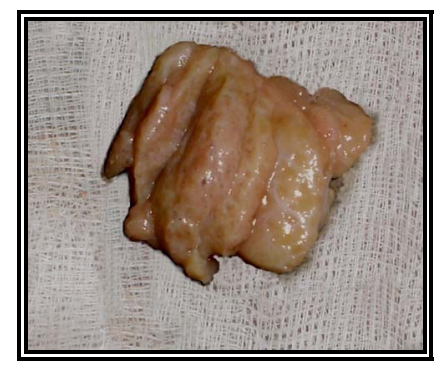

Figure 2. Sample 3, longitudinally cut into slices of equal thickness. 
tions of the tumor were required), and the other fractions separated from the tumor were prepared for other studies. When the fractions for stereology were too large, each slice was further cut and separated into fractions in the same way (with a random numbers table), causing the smaller samples to be even more randomly distributed.

d) Separation of new samples from the remaining fraction of the tumor: First, samples that were approximately $1 \mathrm{~cm}$ from the center of the tumor were selected (when possible) and submitted along with the skin for histological analysis and verification of the edges of the surgical margin. Then, the samples were carefully separated for cytogenetic analysis (by cell culture), in which the degree of contamination should be zero. The samples to be used for RT-PCR analysis were separated soon after and shipped in liquid nitrogen.

The fragments destined for stereology, which were previously selected using the random numbers table, were again selected in smaller fractions, placed in $4 \%$ formaldehyde and refrigerated.

\subsection{Weighing of Fragments}

All fragments were weighed prior to distribution for the different analyses on a precision scale (Ohaus Scout ${ }^{\mathrm{TM}}$ Pro $\left.{ }^{\circledR}-200 \mathrm{~g}\right)$.

\subsection{Collection Specifications}

Because the samples were sent for several analyses, some collection specifications had to be recognized. These specifications are described below and summarized in Table 2.

1) For cell culture, the fragment needed to be $3 \mathrm{~cm}^{3}$, harvested from the center of the tumor without skin or areas of necrosis into a tube with culture liquid [RPM IR10 (10\% FBS) $+10 \mu$ L Penicilin-Streptomycin].

2) For cytogenetic analysis, samples of $5 \mathrm{~mm}^{3}$ were harvested from the center of the tumor without skin or areas of necrosis into an empty and sterile Eppendorf tube placed in an empty ice chest.
3) For $R T-P C R$, the sample fragments were preferably $1 \mathrm{~cm}^{3}$, harvested from the center of the tumor without skin or areas of necrosis into an empty and sterile Eppendorf tube and then immersed in liquid nitrogen.

4) For histopathological analysis, we sent the largest possible number of samples. Fragments were ideally 1 $\mathrm{cm}^{3}$ and were collected from the transition area (containing a portion of the affected tissue and some healthy tissue). Pre-fixation was performed immediately after removing the sample by placing the fragments in a collection bottle with a $10 \%$ neutral buffered formalin solution. The samples were maintained in this solution for at least 24 hours; this procedure is ideal for the fixation of small samples. We tried to use a volume of fixative that was 10 - 50 times the volume of the sample (or samples) in the bottle. The bottle was preferably large, wide-mouthed, well enclosed and identified with the sample name, number e other identifications (surgeon, date, etc.).

5) Because samples sent for stereological analysis should always be selected at random, the initial slices (which determine the separation of the random fraction) were always the first to be separated. For a new random subdivision of the material, selected fragments were then cut in a tissue-slider (Figure 3) such that all of the new fragments had the same thickness $(1 \mathrm{~mm})$; these fragments were properly refrigerated in $4 \%$ formaldehyde.

For identification, the registration number of the animal whose tumor was excised was displayed on all samples, regardless of their destination. This registration file contained all of the relevant clinical information regarding the animal and the collected material.

\subsection{Questionnaires}

To analyze the importance of the collected material and the relevance of this project, a questionnaire was sent to each researcher who received our prepared material and to all surgeons who excised a tumor for this project. The questionnaires addressed the usefulness of the material sent for laboratory processing and the surgeons' interest in our purpose. The researcher provide us information

Table 2. Collection specifications for each sample destination.

\begin{tabular}{|c|c|c|c|c|}
\hline & Number of samples & Size of samples & Location of the tumor & Solution \\
\hline Cell culture & 1 & $3 \mathrm{~cm}^{3}$ & $\begin{array}{l}\text { Center-without necrosis } \\
\text { or skin }\end{array}$ & $\begin{array}{l}\text { Culture liquid [RPM I - R10 } \\
(10 \% \text { FBS })+10 \mu \mathrm{L} \text { Antibiotic] }\end{array}$ \\
\hline $\begin{array}{l}\text { Cytogenetic } \\
\text { analysis }\end{array}$ & 1 & $5 \mathrm{~mm}^{3}$ & $\begin{array}{c}\text { Center-without necrosis } \\
\text { or skin }\end{array}$ & Empty and sterile Eppendorf tube \\
\hline RT-PCR & 1 & $1 \mathrm{~cm}^{3}$ & $\begin{array}{c}\text { Center-without necrosis } \\
\text { or skin }\end{array}$ & Liquid nitrogen \\
\hline Histopathological & 1 or more & at least $1 \mathrm{~cm}^{3}$ & $\begin{array}{c}\text { Transition area, center and } \\
\text { surgical margins }\end{array}$ & $\begin{array}{l}10 \% \text { neutral buffered formalin- } \\
\text { room temperature }\end{array}$ \\
\hline Stereological & $\begin{array}{l}1 \text { or more-by random } \\
\text { selection }\end{array}$ & $\begin{array}{l}\text { Each sample cut into } 1 \\
\text { mm slices (tissue slider) }\end{array}$ & Random selection & $\begin{array}{l}4 \% \text { formaldehyde-room } \\
\text { temperature }\end{array}$ \\
\hline
\end{tabular}



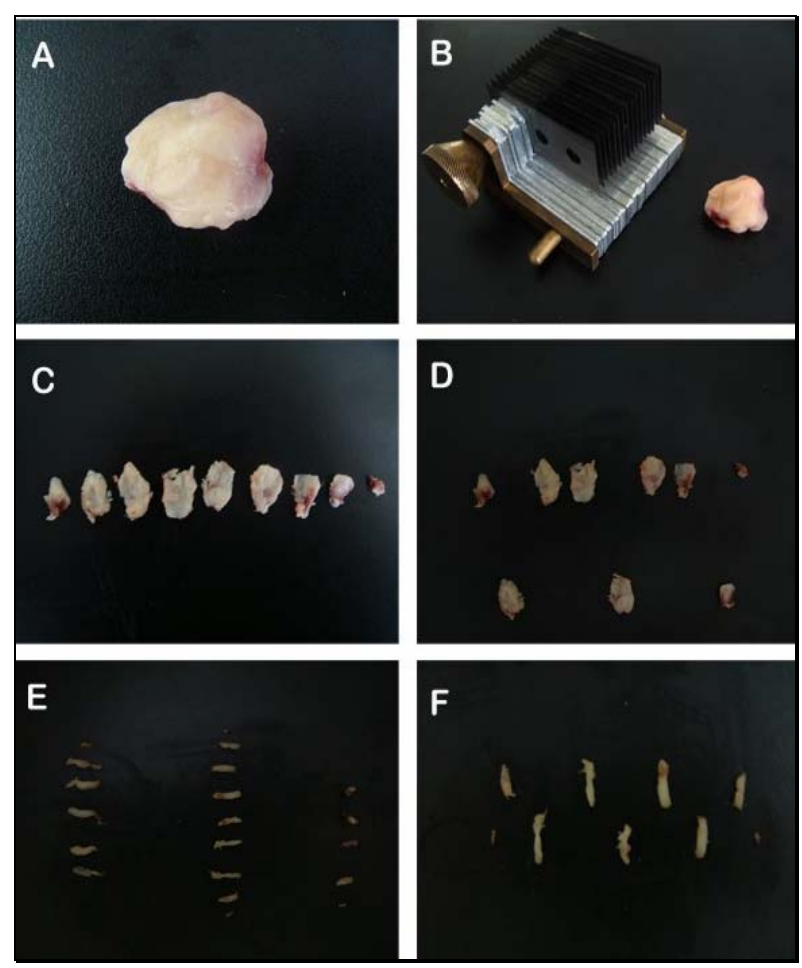

Figure 3. Photograph depicting the sequence of sampling of the tumor. The tumor without capsule or skin (A); preparation for cutting the tumor sections with the anti-thetic unit tissue slider (2 mm) (B); tumor sections in sequence (C); fraction of sections sampled (sections 2,5 and 8 ) (white arrow) (D); each section was also cut into bars with a tissue slider (2 mm) (E); and fraction sampled the bars (bar 2) (white arrow) (F).

about the quality of the sent material, providing a graduation from $0-10$. We collected these information, and considered three degrees: as Good all the material receiving a $8-10$, as average/regular receiving $5-7$ and as poor receiving below 5 .

\section{Results}

\subsection{Sampling}

The materials were collected after surgical excision, and the data related to the tissues are summarized in Table 3.

The following percentages represent the pattern of the breeds of the animals examined during this study: 41.67\% Boxer, $16.67 \%$ Labrador Retriever, 8.33\% Doberman Pinscher, $11.10 \%$ Mixed Breed, 5.55\% Siberian Husky, 2.78\% Dachshund, 2.78\% German Shepherd, 2.78\% Brazilian Terrier, 2.78\% Maltese, 2.78\% Pit Bull, and $2.78 \%$ Basset Hound.

Among the mast cell tissues that were collected, the samples were quite heterogeneous in their form and appearance, both between samples taken from different animals and within samples of the same formation. The formations were gelatinous or firm, and these formations were often seen in very similar proportions regardless of the degree of malignancy determined by histopathology. The sizes of the tumors were observed to be very different (Table 3). We found some large formations, while the size of others was so small that fractionation and distribution to all analyses was difficult.

\subsection{Questionaries for the Researchers}

\subsubsection{Researcher 1-Breakdown for Cytogenetic Analysis of Chromosomes}

Analysis of the quality of the submitted material indicated that $90.9 \%$ of the samples were considered to be of good quality, $4.5 \%$ (equivalent to one sample) was considered to be of regular quality and only $4.5 \%$ (equivalent to one sample) was considered to be of poor quality. Only one sample was eliminated by the researcher; the quality of this sample was considered to be poor because contained insufficient material for analysis (sample 11, which had a weight of $0.57 \mathrm{~g}$ ). This sample came from one of the smallest tumors collected in this study.

\subsubsection{Researcher 2-Quantification of Gene Expression of CX 43, 32 and E-Cadherin in Canine Mast Cell Tumors (RT-PCR)}

Analysis of the quality of the submitted material indicated that $95.5 \%$ of the samples were considered to be of good quality, and only $4.5 \%$ (equivalent to one sample, number 11) were considered to be of regular quality. No sample was considered to be of poor quality.

The percentage of sample exclusion was $27 \%$ (equivalent to six samples), and the reason for each exclusion is provided below:

Sample 3: small fragment;

Sample 5: small fragment;

Sample 8: minimal RNA obtained after amplification;

Sample 16: presence of hair surrounding the tumorno amplified RNA;

Sample 17: no amplified RNA;

Sample 20: little RNA obtained after amplification.

\subsubsection{Histopathology Laboratory}

From the pathologic reports, we assessed only the degree of malignancy of each tumor, which was based on the cellular differentiation characteristics [19].

In the 36 samples analyzed and classified according to Patnaik [19] we found five samples (13.89\%) from grade I tumors, 28 samples (77.78\%) from grade II and three samples $(8.83 \%)$ from grade III tumors. Only one sample (number 2) was reported as an indeterminate histopathologic grade. These data are summarized in Table 4.

After submitting the first samples, the professionals responsible for the histological analysis started to request samples larger than those that we were initially sending (1 $\mathrm{cm})$. We tried to adjust our method to satisfy this request. 
Table 3. Distribution of cases of mast cell tumor based on age, sex, breed, number of tumors, total weight and destination from the Service of Small Animal Surgery-Veterinary Hospital-School of Veterinary Medicine, University of São Paulo over a period of 20 months.

\begin{tabular}{|c|c|c|c|c|c|c|}
\hline Sample & Age (years) & Gender & Breed & Tumor Total Weight (g) & No of Tumors & Destiny \\
\hline 1 & 10 & $\mathrm{~F}$ & Dachshund & 46 & 1 & I, II, III, IV \\
\hline 2 & 8 & $\mathrm{~F}$ & Mixed breed & 152.53 & 1 & I, II, III, IV \\
\hline 3 & 9 & M & Boxer & 0.87 & 1 & I, II, III, IV \\
\hline 4 & 7 & $\mathrm{~F}$ & Boxer & 2.10 & 1 & I, II, III, IV \\
\hline 5 & 7 & $\mathrm{~F}$ & Boxer & 0.46 & 1 & I, II, IV \\
\hline 6 & 8 & M & Boxer & 0.52 & 1 & I, II, III, IV \\
\hline 7 & 6.5 & M & Mixed breed & 40.5 & 1 & I, II, III, IV \\
\hline 8 & 9.5 & M & Labrador Retriever & 10,36 & 1 & I, II, III, IV \\
\hline 9 & 6.5 & $\mathrm{~F}$ & German Shepherd Dog & 4.34 & 1 & I, II, IV \\
\hline 10 & 12 & $\mathrm{~F}$ & Brazilian Terrier & 4.68 & 1 & I, II, IV \\
\hline 11 & 8 & M & Labrador Retriever & 0.57 & 1 & I, II, III, IV \\
\hline 12 & 14 & $\mathrm{~F}$ & Doberman Pinscher & 10.39 & 2 & I, II, IV \\
\hline 13 & 6.5 & $\mathrm{~F}$ & Boxer & 10.8 & 1 & I, II, III, IV \\
\hline 14 & 9 & $\mathrm{~F}$ & Labrador Retriever & 44.12 & 1 & I, II, III, IV \\
\hline 15 & 9 & M & Boxer & 500 & 1 & I, II, III, IV \\
\hline 16 & 7 & M & Boxer & 1.05 & 1 & I, II, III, IV \\
\hline 17 & 7 & M & Boxer & 145.7 & 1 & I, II, III, IV \\
\hline 18 & 5 & $\mathrm{~F}$ & Maltese & 5.63 & 1 & I, II, IV \\
\hline 19 & - & $\mathrm{F}$ & Doberman Pinscher & 4.54 & 1 & I, II, III, IV \\
\hline 20 & 7 & M & Boxer & 0.17 & 2 & I, II, III, IV \\
\hline 21 & 10 & $\mathrm{~F}$ & Boxer & 50.4 & 6 & I, II \\
\hline 22 & 4 & $\mathrm{~F}$ & Boxer & 7.22 & 1 & I, II, III, IV \\
\hline 23 & 4 & M & LabradorRetriever & 118.62 & 1 & I, II, III, IV \\
\hline 24 & 7 & M & Pit Bull & 0.85 & 2 & I, II, IV \\
\hline 25 & 9 & M & Mixed breed & 15.09 & 4 & I, II, III, IV \\
\hline 26 & 7 & $\mathrm{~F}$ & Mixed breed & & 1 & I, II, III, IV \\
\hline 27 & 7 & $\mathrm{~F}$ & Boxer & 0.24 & 2 & I, II, III, IV \\
\hline 28 & 9 & $\mathrm{~F}$ & Doberman Pinscher & 4.03 & 1 & I, II, III, IV \\
\hline 29 & 3 & $\mathrm{~F}$ & Boxer & 2.88 & 1 & I, II, III, IV \\
\hline 30 & 7 & M & Siberian Husky & 143.46 & 2 & I, II, IV \\
\hline 31 & 10 & M & Labrador & 20.83 & 1 & I, II, IV \\
\hline 32 & 7 & M & Siberian Husky & 143.46 & 2 & I, II, IV \\
\hline 33 & 9 & $\mathrm{~F}$ & Boxer & 13.38 & 2 & I, II, IV \\
\hline 34 & 7 & $\mathrm{~F}$ & Boxer & 0.66 & 2 & I, II \\
\hline 35 & 10 & $\mathrm{~F}$ & Labrador Retriever & 45.85 & 1 & I, II, IV \\
\hline 36 & 6 & $\mathrm{~F}$ & Basset Hound & 12.32 & 1 & I, II, III, IV \\
\hline
\end{tabular}

I-stereology; II-histopathology; III—cell culture and disaggregation for cytogenetic analysis of chromosomes; IV-Cell Lysis RNA collection from tumor cells for gene expression by RT-PCR F: female; M: male. 
Table 4. Histopathologic reports of the degree of cellular differentiation [19] in the collected mast cell tumors.

\begin{tabular}{|c|c|}
\hline Sample & Mast Cell Tumor Degree \\
\hline 1 & G3 \\
\hline 2 & G2 \\
\hline 3 & G1 \\
\hline 4 & $\mathrm{G} 2$ \\
\hline 5 & $\mathrm{G} 2$ \\
\hline 6 & $\mathrm{G} 2$ \\
\hline 7 & $\mathrm{G} 2$ \\
\hline 8 & G2 \\
\hline 9 & $\mathrm{G} 2$ \\
\hline 10 & $\mathrm{G} 2$ \\
\hline 11 & $\mathrm{G} 2$ \\
\hline 12 & $\mathrm{G} 2$ \\
\hline 13 & $\mathrm{G} 2$ \\
\hline 14 & $\mathrm{G} 2$ \\
\hline 15 & G3 \\
\hline 16 & G1 \\
\hline 17 & $\mathrm{G} 2$ \\
\hline 18 & $\mathrm{G} 2$ \\
\hline 19 & $\mathrm{G} 2$ \\
\hline 20 & $\mathrm{G} 2$ \\
\hline 21 & $\mathrm{G} 1 / \mathrm{G} 2$ \\
\hline 22 & $\mathrm{G} 2$ \\
\hline 23 & $\mathrm{G} 2$ \\
\hline 24 & Undetermined \\
\hline 25 & $\mathrm{G} 2$ \\
\hline 26 & $\mathrm{G} 2$ \\
\hline 27 & $\mathrm{G} 2$ \\
\hline 28 & G2 \\
\hline 29 & G1 \\
\hline 30 & $\mathrm{G} 2$ \\
\hline 31 & $\mathrm{G} 2$ \\
\hline 32 & $\mathrm{G} 2$ \\
\hline 33 & $\mathrm{G} 2$ \\
\hline 34 & G1 \\
\hline 35 & G2 \\
\hline 36 & $\mathrm{G} 2$ \\
\hline
\end{tabular}

\subsubsection{Stereology Laboratory}

Among the material that was submitted, $100 \%$ of the samples were considered to be of good quality. No sample was considered to be of regular or poor quality. None of the samples were discarded for reasons that may be related to the sample collection.

\subsection{Questionnaires for Surgeons}

Three surgeons in the Department of Small Animal Surgery-Veterinary Hospital-School of Veterinary Medicine, University of São Paulo had performed the excision surgeries of this study, and all of them answered the following questions, and the results are presented below.

1) Time of surgery: The average surgery time was 1.45 $\mathrm{h}$ (approximately 1 hour and 27 minutes) with a standard deviation of 0.6 .

2) The importance of ensuring proper collection: even before this project, $100 \%$ of surgeons questioned declared to have an interest in what could be done to ensure proper collection, primarily because better samples would allow better assessment of the clinical prognosis of the patient.

3) Time for tumor dissection, proper storage, and submission for analysis: only one of the surgeons who participated in this project stated that the average time to dissect the tumor was between 20 and 30 minutes, depending on the size of the tumor. The other surgeons questioned stated that the material they sent to the laboratory was sent without dissection and was sometimes immersed in $10 \%$ formalin at room temperature for up to 24 hours before being delivered to the laboratory.

4) Cancer surgeries without sending samples to the lab: only one of the surgeons worried about where to send the material for analysis in oncology procedures. The others stated that careful removal of the tumor with an adequate surgical margin is always a concern, but they also indicated that they had participated in surgeries in which sending samples to the laboratory was a concern, at the option of the animal's owner.

5) Surgeons' considerations regarding this work: among the surgeons who participated in this study, $66.67 \%$ considered the need for the presence of a person in the surgical centers who is responsible for sending quality samples to research laboratories to be at least a good idea, and $33.33 \%$ considered the presence of such a person to be necessary. None of the surgeons considered such a person to be expendable.

\section{Discussion}

No studies exist in the veterinary medicine literature that have quantified the percentage of error in histopathological analysis that results from inappropriate preparation of the samples. In contrast, some important studies 
have addressed this theme in human medicine [20-22]. In our experience, these errors do exist in veterinary medicine and are as concerning as in human medicine. Because of poor samples we can have later or even wrong diagnosis, bad treatment choices or errors in establishing the animal prognosis, Although we have no literature data, in our experience, most of these errors are caused by inappropriate preparation and storage of the samples. In this work, our objective was to collect suitable material and manage its distribution to different laboratories.

For samples designated for histopathology, we tried to meet the demand from professionals to increase the size of the samples. Therefore, we started to separate these materials following the separation for stereology. Thus, we gave preference to histopathological study when the tumor was too small. For mast cell tumors, the recognized ideal is to send more than one fragment (ideally 3 4) of approximately $2 \mathrm{~cm}^{3}$ for histopathology that were preferably isolated from regions which are morphologically quite different. This isolation from different regions is particularly important in heterogeneous tumors such as mast cell tumors. Several authors have confirmed and described this characteristic $[2,16,24,25]$. The heterogeneous form of these tumors (within the same tumor) does not allow the collection of very small samples; therefore, a great possibility exists of separating only a portion rich in material and necrotic tissue, which may produce inconclusive findings regarding the malignancy of the tumor. After adapting to this procedure, the pathology service had no difficulty in properly evaluating the tumors and in issuing the reports.

The analyses of all of the samples were consistent with the histology, cytology and fine needle aspiration results. Thus, all features that were removed and sent for the studies were indeed mast cells. These data demonstrate the reliability of the initial diagnosis by aspiration cytology, as previously shown by several authors [2,3,24-26].

The samples for cell culture and cytogenetic analysis also require the greatest possible amount of material. In only one sample $(6.25 \%)$, the submitted material was classified as having poor quality and was discarded due to insufficient material. While this poor material alarmed us, it is important to report that it is often not feasible to collect the intended quantity of material suitable for all protocols because the tumor is too small or has a large amount of connective tissue intermingled with the tumor. Moreover, most of the submitted samples were classified as having good quality $(87.5 \%)$. For now, the researchers noted no difference in the quality of the samples, which may have been justified by improvements in readiness and dispatch.

At the request of the researcher, samples were chosen from the soft parts of the tumor for the RT-PCR analysis.
The percentage of samples discarded in this procedure was $27 \%$. These exclusions were considered expected by the researcher (and are related to the technique used for RT-PCR), We would like to emphasize the researcher's observations from our questionnaire:

- "Samples generally considered excellent allowing completion of the procedure (amplification by real-time)".

- "The extraction of RNA can be difficult from small tumors by virtue of the small quantitiy of material. Additionally, the presence of hair in the sample can also make the RNA extraction more difficult".

As previously mentioned, the amount of sample submitted is not always under our control, because the tumors can be very small, and preference is given to sending specimens to histopathology, which can provide important data about the patient's prognosis. Regarding the comment about the presence of hair, we encountered this problem in two of the tumors sampled in this work; in these cases, the hairs were interspersed in the tumor and could not be separated, even in the deepest parts.

The questionnaires sent to the surgeons indicated that the average time of surgery is 1 hour and 27 minutes and that this time varies substantially and is related to the size of the tumor, the technique used and the reconstructive procedure performed. Thus, one can observe that some surgeries took up to 2.5 hours to complete, and the preparation and submission of samples from these surgeries to certain analyses (such as extraction of RNA) would suffer significant delay.

Regarding stereological cuts, not all of the samples were distributed to the stereological study because this analysis is more detailed and requires specific equipment. Thus, stereological studies often contain representative samples from each group studied; in our case, some samples were randomly selected to have a homogeneous number of cases from each degree. All surgeons have an interest in ensuring proper collection of material to be sent to histopathology, primarily because histopathologists can evaluate the patient's prognosis. However, we should highlight here that most respondents agree that the material they sent to the laboratory was not dissected and that the material was sometimes immersed in $10 \%$ formalin at room temperature for up to 24 hours before delivery to the laboratory. This procedure clearly compromises the quality of the material for some analyses (including stereological study) because a tumor that is still wrapped in skin does not receive adequate fixation even when immersed in $10 \%$ formalin. Therefore, the continued need for a person responsible for proper dissection and immediate dispatch of samples to the laboratory in the surgical centers should be noted, if only for the purposes of analyzing the tumor for clinical prognosis.

Among surgeons who participated in this work, $66.67 \%$ 
found the necessity for a person who is responseble for sending quality samples to research laboratories to be present in the surgical room to be a good idea, and $33.33 \%$ considered this person to be required. We should emphasize that none of the surgeons considered the presence of such a person within the surgical team to be expendable. These data have great significance, and this work aroused interest and reminded surgeons of the importance of the proper collection and storage of the tumor material. The presence of a responsible person who is in charge of this procedure is believed to be needed or is at least an at least an important idea do consider.

\section{Conclusions}

In completing this study, we cooperated with various research teams that had varied approaches to collection and analysis of material for the study of canine mast cell tumors. We attempted to reduce sampling errors in the dispatch of material to research and histological studies. We emphasize the importance of combining the needs of the different groups involved in the diagnosis of cancer patients, including the surgical team and the clinical and research laboratories.

We suggest that all institutions create protocols for distributing material, such as that which was followed in this work. These protocols would enable the pathologists and the surgical team to establish a standard sample size and number, which could decrease the contribution of the surgical team to errors in histopathological studies.

\section{REFERENCES}

[1] B. Séguin, N. F. Leibman, V. S. Bregazzi, G. K. Ogilvie, B. E. Powers, W. S. Dernell, M. J. Fettman and S. J. Withrow, "Clinical Outcome of Dogs with Grade II Mast Cell Tumors Treated with Surgery Alone: 55 Cases (19961999)," Journal of the American Veterinary Medical Association, Vol. 218, No. 7, 2001, pp. 1120-1123. doi:10.2460/javma.2001.218.1120

[2] D. Slatter, "Textbook of Small Animal Surgery," 3rd Edition, Elsevier Science, New York, 2002.

[3] H. D. Thamm and M. D Vail, "Mast Cell Tumors," In: S. J. Withrow and E. G. Maceven, Eds., Small Animal Clinical Oncology, 3rd Edition, Saunders Company, Philadelphia, 2001, pp. 261-282.

[4] G. M. Michels, D. W. Knapp, D. B. Denicola, N. Glickman and P. Bonney, "Prognosis Following Surgical Excision of Canine Cutaneous Mast Cell Tumors with histopathologically Tumor-Free versus Nontumor-Free Margins: A Retrospective Study of 31 Cases," Journal of the American Animal Hospital Association, Vol. 38, No. 5, 2002, pp. 458-466.

[5] V. M. D. C. Weisse and C. M. V. K. Sorenmo, "Recurrence Rates and Sites for Grade II Canine Cutaneous Mast Cell Tumors Following Complete Surgical Exci- sion," Journal of the American Animal Hospital Association, Vol. 38, No. 1, 2002, pp. 71-73.

[6] J. J. Abadie, M. A. Amardeilh and M. E. Delverdier, "Immunohistochemical Detection of Proliferating Cell Nuclear Antigen and Ki-67 in Mast Cell Tumors from Dogs," Journal of the American Animal Hospital Association, Vol. 215, No. 11, 1999, pp. 1629-1634.

[7] H. Sakai, A. Noda, N. Shirai, et al., "Proliferative Activity of Canine Mast Cell Tumours Evaluated by Bromodeoxyuridine Incorporation and Ki-67 Expression," Journal of Comparative Pathology, Vol. 127, No. 4, 2002, pp. 233-238. doi:10.1053/jcpa.2002.0586

[8] J. P. Simoes, P. Schoning and M. Butine, "Prognosis of Canine Mast Cell Tumors: A Comparison of Three Methods," Veterinary Pathology, Vol. 31, No. 6, 1994, pp. 637-647. doi:10.1177/030098589403100602

[9] L. D. Kravis, D. M. Vail, W. C. Kissebert, et al., "Frequency of Argyrophilic Nucleolar Organizer Regions in Fine-Needle Aspirates and Biopsy Specimens from Mast Cell Tumors in Dogs," Journal of the American Veterinary Medical Association, Vol. 209, No. 8, 1996, pp. 14181420.

[10] R. D. Ayl, C. G. Couto, A. S. Hammer, S. Weisbrode, J. G. Ericson and L. Mathes, "Correlation of DNA Ploidy to Tumor Histologic Grade, Clinical Variables, and Survival in Dogs with Mast Cell Tumors," Veterinary Pathology, Vol. 29, No. 5, 1992, pp. 386-390. doi: $10.1177 / 030098589202900503$

[11] R. Preziosi, G. Sarli and M. Paltrinieri, "Prognostic Value of Intratumoral Vessel Density in Cutaneous Mast Cell Tumors of the Dog," Journal of Comparative Pathology, Vol. 130, No. 2-3, 2004, pp. 143-151. doi:10.1016/i.jcpa.2003.10.003

[12] P. E. Ginn, L. E. Fox, J. C. Brower, A. Gaskin, I. D. Kurzman and P. S. Kubilis, "Immunohistochemical Detection of p53 Tumor-Suppressor Protein Is a Poor Indicator of Prognosis for Canine Cutaneous Mast Cell Tumors," Veterinary Pathology, Vol. 37, No. 1, 2000, pp. 33-39. doi:10.1354/vp.37-1-33

[13] M. H. Jaffe, G. Hosgood, H. W. Taylor, S. C Kerwin, C. S. Hedlund, M. K. Lopez, J. R. Davidson, D. M. Miller and M. Paranjpe, "Immunohistochemical and Clinical Evaluation of p53 in Canine Cutaneous Mast Cell Tumors," Veterinary Pathology, Vol. 37, No. 1, 2000, pp. 40-46. doi:10.1354/vp.37-1-40

[14] M. Kiupel, J. D. Webster, J. B. Kaneene, et al., "The Use of KIT and Tryptase Expression Patterns as Prognostic Tools for Canine Cutaneous Mast Cell Tumors," Veterinary Pathology, Vol. 41, No. 4, 2004, pp. 371-377. doi:10.1354/vp.41-4-371

[15] J. D. Webster, V. Yuzbasiyan-Gurkan, J. B. Kaneene, et al., "The Role of c-KIT in Tumorigenesis: Evaluation in Canine Cutaneous Mast Cell Tumors," Neoplasia, Vol. 8, No. 2, 2006, pp. 104-111. doi:10.1593/neo.05622

[16] R. F. Strefezzi, G. J. Xavier and J. L. Catão-Dias, "Morphometry of Canine Cutaneous Mast Cell Tumors," Veterinary Pathology, Vol. 40, No. 3, 2003, pp. 268-275. doi:10.1354/vp.40-3-268 
[17] M. Kiupel, J. D. Webster, R. A. Miller and J. B. Kaneene, "Impact of Tumour Depth, Tumour Location and Multiple Synchronous Masses on the Prognosis of CANINE cutaneous Mast Cell Tumours," Journal of Veterinary Medicine Series A, Vol. 52, No. 6, 2005, pp. 280-286. doi:10.1111/j.1439-0442.2005.00726.x

[18] A. K. Cahalane, S. Payne, L. G. Barber, et al., "Prognostic Factors for Survival of Dogs with Inguinal and Perineal Mast Cell Tumors Treated Surgically with or without Adjunctive Treatment: 68 Cases (1994-2002)," Journal of the American Veterinary Medical Association, Vol. 225, No. 3, 2004, pp. 401-408. doi:10.2460/javma.2004.225.401

[19] A. K. Patnaik, W. J. Ehler and E. G. Macewen, "Canine Cutaneous Mast Cell Tumor: Morphologic Grading and Survival Time in 83 Dogs," Veterinary Pathology, Vol. 21, No. 5, 1984, pp. 469-474.

[20] S. S. Raab, R. E. Nakhleh and S. G. Ruby, "Patient Safety in Anatomic Pathology: Measuring Discrepancy Frequencies and Causes," Archives of Pathology \& Laboratory Medicine, Vol. 129, No. 4, 2005, pp. 459-466.

[21] S. S. Raab, D. M. Grzybicki, J. E. Janosky et al., "Clinical Impact and Frequency of Anatomic Pathology Erros in Cancer Diagnosis," American Cancer Society, Vol. 104, No. 10, 2005, pp. 2205-2213.

[22] S. S. Raab, "Improving Patient Safety by Examining Pathology Errors," Clinics in Laboratory Medicine, Vol. 24, No. 4, 2004, pp. 849-886. doi:10.1016/j.cll.2004.05.014

[23] K. Lindblad-Toh, C. M. Wade, T. S. Mikkelsen, E. K. Karlsson, D. B. Jaffe, M. Kamal, M. Clamp, J. L. Chang, E. J. Kulbokas, M. C. Zody, et al., "Genome Sequence, Comparative Analysis and Haplotype Structure of the Domestic Dog," Nature, Vol. 438, No. 7069, 2005, pp. 803-819. doi:10.1038/nature04338

[24] M. H. Goldschmidt and M. J. Hendrick, "Tumors of the Skin and Soft Tissues," In: D. J. Meuten, "Tumors in Domestic Animals," 4th Edition, Iowa State Press, Iowa, 2002, pp. 105-107. doi:10.1002/9780470376928.ch2

[25] J. M. Cullen, R. Page and W. Misdorp, "An Overview of Cancer Pathogenesis, Diagnosis, and Management," In: D. J. Meuten, Ed., Tumors in Domestic Animals, 4th Edition, Iowa State Press, Iowa, 2002, pp. 3-27.

[26] K. S. Rogers, "Mast Cell Tumors: Dilemmas of Diagnosis and Treatment," Veterinary Clinics of North America, Vol. 26, No. 1, 1996, pp. 87-102. 